\title{
Weak relationships of continuous forest management intensity and remotely sensed stand structural complexity in temperate mountain forests
}

\author{
Thomas Asbeck ${ }^{1}$ (D) Julian Frey ${ }^{2}$ (1)
}

Received: 18 September 2020 / Revised: 14 January 2021 / Accepted: 18 January 2021 / Published online: 13 February 2021

(c) The Author(s) 2021

\begin{abstract}
Understanding the relationship of stand structural complexity and forest management is relevant to create desired stand structures by adapting management strategies under changing disturbance scenarios and climatic conditions. To overcome difficulties in differentiating between strict categories of silvicultural practices and to describe the impact of forest management more appropriate, we used a continuous indicator of forest management intensity (ForMI). The ForMI consists of three components including volumes of natural deadwood, non-native tree species and harvested trees. There are a great number of approaches to quantify stand structure; here we used the recently established stand structural complexity index (SSCI) which represents a density-dependent as well as vertical measure of complexity based on the distribution of points in 3D space inventoried by terrestrial laser scanning. The data collection took place in 135 one-hectare plots managed under close-to-nature forest management (CTNFM) located in the Black Forest, Germany. We build generalized additive models to test the relationship of the SSCI with the ForMI. The model results did not prove a significant relationship between the SSCI and the ForMI, but components of the ForMI showed significant relationships to the SSCI. Our results indicate that the relationship between stand structural complexity and forest management intensity is, while plausible, not trivial to demonstrate. We conclude that forest managers have a relatively wide range of choices in CTNFM to adapt forests within a similar range of management intensity as presented here to future challenges, since management intensity does not change the forest structure drastically.
\end{abstract}

Keywords Close-to-nature forest management (CTNFM) · Black forest · Terrestrial laser scanning (TLS) · Effective number of layers (ENL)

\section{Introduction}

Understanding the relationship of stand structural complexity and forest management intensity is especially relevant in the context of altering disturbance scenarios that we face under climate change to create desired stand structures by adapting management strategies (Seidl et al. 2017; Augustynczik et al. 2019; Seidel et al. 2019a; Senf et al.

Communicated by Christian Ammer.

Thomas Asbeck

thomas.asbeck@waldbau.uni-freiburg.de

1 Chair of silviculture, University of Freiburg, Tennenbacherstr. 4, 79106 Freiburg, Germany

2 Forest Growth and Dendroecology, University of Freiburg, Tennenbacher Straße 4, 79106 Freiburg, Germany
2020). Analyzing the relationship of stand structure and forest management is hence relevant under these changing environmental conditions to monitor consequences of disturbances in differently managed forests. This allows to adapt management strategies according to these new challenges to create resilient forest ecosystems (Ćosović et al. 2020; Atkins et al. 2020; Holzwarth et al. 2020). Improving the understanding of the influence of management intensity of a specific silvicultural approach on the stand structure allows managers to select the right tools to maintain the desired stand structure (Messier et al. 2013; Schall et al. 2018a). In addition, stand structure is an important factor for the associated biodiversity (Schall et al. 2018b, 2020; Frey et al. 2020; Ćosović et al. 2020). The relationship of stand structure and forest management has received attention in forest science for a long time (Neumann and Starlinger 2001; Berryman and McCune 2006; Ehbrecht et al. 2017; Stiers et al. 
2018). Different management systems are usually the basis for comparisons of forest management and stand structure (Gadow et al. 2012; del Río et al. 2016; Schall et al. 2018b; Stiers et al. 2018). Most commonly uneven-aged and evenaged systems are compared in studies of stand structure in temperate forests of central Europe (Peck et al. 2014; Schall et al. 2018b; Stiers et al. 2018). However, there is a large variety of implementations and silvicultural practices of these two generally diverging forest management systems. One of these management systems is close-to-nature forest management (CTNFM) that is practiced in central Europe (Bauhus et al. 2013). The usual idea of CTNFM focuses on the following aspects: (a) use of site-adapted tree species, typically of the natural forest vegetation, (b) promotion of mixed and structurally diverse forests, (c) avoidance of large canopy openings such as clear-cuts, (d) employment of natural processes such as natural regeneration, self-thinning and self-pruning, and (e) silvicultural focus on individual trees rather than stands (Bauhus et al. 2013; Brang et al. 2014). Congruent structural differences between even-aged and uneven-aged management, cannot be detected in some cases when using remote sensing techniques (Stiers et al. 2018), or are particular to the inventoried type of forests (Schall et al. 2018b). The differentiation between even- and uneven-aged stands might be hampered by factors as stands originating from even-aged systems being transferred into uneven-aged systems or the spatial scale on which the management is planned.

To overcome the difficulty of differentiating between strict categories of silvicultural practices and to be able to describe the management in an improved way, we use a continuous indicator of forest management intensity. This Forest Management Intensity Index (ForMI) is based on field inventory data that delivers a better representation of what happens on the ground (Kahl and Bauhus 2014). The index incorporates three important components of forest structure: (a) the proportion of harvested tree volume compared to the theoretical maximum volume which is a proxy for the potential cumulative merchantable volume (Iharv), (b) the proportion of stand volume in tree species that are not part of the natural forest community (Inonat) and (c) the proportion of lying deadwood showing signs of saw cuts compared to deadwood originating from natural disturbances (Idwcut).

The second difficulty in studies on stand structure in relation to forest management is how to quantify the structure. There is a variety of "traditional" forest attributes such as basal area or tree height distributions, as well as a large range of indices that translate common attributes into structural or spatial indices (Neumann and Starlinger 2001; Szmyt 2014). Several such comprehensive indices estimate the structural diversity of forests (e.g., McElhinny et al. 2006) while others have been established for particular forest types and regions which focus mainly on one tree species, stand type or age structure (Acker et al. 1998; Sabatini et al. 2015). Recently, close range remote sensing options such as unmanned-aerial vehicles (UAV) or terrestrial laser scanning (TLS) allowed additional descriptions of stand structure (Ehbrecht et al. 2017; Frey et al. 2020). TLS inventories the geometry of the environment directly by laser distance measurements. By emitting a laser pulse in a known direction and measuring the time until it returns allows the detection of the position of an obstacle relative to the device with millimeter accuracy. A modern scanner is able to take millions of such measurements within a minute to give a full $360^{\circ} 3 \mathrm{D}$ representation of its' surrounding. Using such models from sensors enables us to derive structural estimates of the forest directly from the data without manual interpretation (Seidel et al. 2016, 2019b; Frey et al. 2020). Here, we propose to use the stand structural complexity index (SSCI) as described by Ehbrecht et al. (2017). This index represents a density-dependent as well as vertical measure of complexity based on the distribution of points in 3D space. The SSCI is sensitive to the tree species diversity and mixing (Ehbrecht et al. 2017; Juchheim et al. 2019), the absence of forest management in European beech (Fagus sylvatica L.) forest (Stiers et al. 2018), is linked to the microclimate within the stand (Ehbrecht et al. 2017, 2019) and reflects the perception of forest experts with regard to the stand structure (Frey et al. 2019).

Close relationships of forest management influence on stand structural complexity have not been shown in an earlier study for temperate forests (Storch et al. 2018), as indexes combine many, to some extent diverging, descriptors of stand structure or might not mirror temporal changes within stands following management interventions closely (e.g., Whitman and Hagan 2007). We assume a peak of complexity at a more intermediate forest management intensity, following the ideas of the intermediate disturbance hypothesis (Townsend et al. 1997). The intermediate disturbance hypothesis is strongly debated (Fox 2013), nevertheless we do expect that low management intensity following for instance a relatively recent (20-40 years) cease of management as well as very intensive management will reduce the stand structural complexity (Fig. 1).

Our hypotheses are that (1) the forest management intensity, as measured by the ForMI, shapes the stand structure represented by the SSCI and has a maximum at an intermediate intensity (Fig. 1); (2) the three components of the ForMI shape parts of the stand structure expressed by components of the SSCI and common stand structural attributes resembling the highest complexity at an intermediate management intensity. We aim to disentangle the influence of forest management intensity in close-to-nature forest management on the remotely sensed stand structural complexity. 


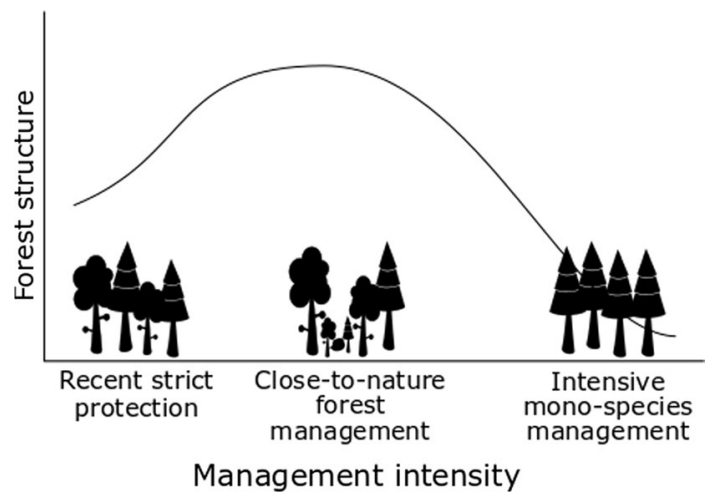

Fig. 1 Conceptual graph of forest structure in relationship to forest management as practiced in our research area. A relatively recent absence of management (20-40 years) reduces the structural complexity and leads to mature, dense stands lacking larger canopy openings. Close-to-nature forest management (CTNFM) opens the canopy and leads to a more diverse structure due to horizontal heterogeneity of layers including gaps with natural regeneration. Intensively managed mono-species stands have a closed canopy and a low structural complexity

\section{Material and methods}

\section{Data collection}

The data were collected within the project "Conservation of Forest Biodiversity in Multiple-Use Landscapes of Central Europe ConFoBi" (Storch et al. 2020). The data collection took place in 135 one-hectare forest plots located on state land in the Black Forest region (Latitude: $47.6^{\circ}-48.3^{\circ} \mathrm{N}$, Longitude: $7.7^{\circ}-8.6^{\circ} \mathrm{E}$, WGS 84 , see Fig. 2). The plot selection followed a landscape gradient of forest cover and a gradient of structural complexity indicated by the number of standing dead trees per plot (Storch et al. 2020). The landscape gradient refers to three categories of forest cover within a $25 \mathrm{~km}$ radius around the center of each plot: $<50 \%$, $50-75 \%$ and $>75 \%$ estimated by GIS raster data, while for the forest structure gradient the plots were grouped by the number of standing dead trees ( $0,1-9$ and 10 or more). All plots are located in stands older than 60 years, thus in mature forests and mostly not older than 120 years and above $500 \mathrm{~m}$ a.s.l. Most of the plots were managed for timber production. The current management system is single-tree selection focusing on target diameters in all plots. Several of the stands originated from planted even-aged Norway spruce (Picea abies (L.)) stands that are consistently managed under close-to-nature forest management and are transferred from even- to uneven-aged systems. The majority of plots were not located in single stands, but included multiple ones of both even-as well as uneven-aged origin, which is why a categorization into a single management type cannot appropriately depict the current management. A few stands are located in recently established (20-40 years) strict-protected areas. The main tree species are Norway spruce (41\%), European beech (22\%) and silver fir (Abies alba Mill., 19\%). A forest inventory that collected traditional forestry parameters was carried out in all plots and the data was used for the following steps of the analyses. We derived the basal area $\left(\mathrm{m}^{2} / \mathrm{ha}\right)$, Gini coefficient of DBH per ha, quadratic mean DBH $(\mathrm{cm})$, number of stems and tree species per ha from the full inventory to show descriptive stand structural attributes common for non-remote sensing structural indices (e.g., McElhinny et al. 2006; del Río et al. 2016).

\section{Forest management intensity index data collection}

To quantify the influence of management on stand structure, we used the forest management intensity index (ForMI) as proposed by Kahl and Bauhus (2014). The data for the proportions of the standing stock for part (a) (Iharv-proportion of harvested tree volume compared to the maximum volume) and (b) (Inonat - proportion of species not belonging to the natural community) were derived from the full forest inventory. The theoretical maximum volume is calculated based on remaining stumps using allometric functions of the respective tree species to assess the volume of the trees that would be present without harvesting. The lying deadwood sampling (Idwcut) of the ForMI was based on the line intersect method, as described by Van Wagner (Van Wagner 1982) and followed a V-transect from the North-East corner to the center of the southern plot border to the North-West corner in each plot. Every piece of deadwood, with a diameter equal to or greater than $7 \mathrm{~cm}$ crossing the transect line was sampled and the origin being artificial or natural was recorded. In a two-meter buffer around the transect line (4-m strip width) all artificial stumps were measured. One of the limitations of the ForMI is that it can only assess forest management up to approximately 40 years in retrospect, since stumps of certain tree species are fully decayed within this period (Kahl and Bauhus 2014).

\section{Remote sensing data collection and calculation of the stand structural complexity index}

Three single terrestrial laser scans (TLS) have been conducted between September 2017 and May 2018 at the center, and at two locations in $50 \mathrm{~m}$ distance from the center toward the north-west and the south-east at every research plot. Each scan was carried out with a Faro Focus 3D 120 (Faro Technologies Inc., Lake Mary, USA) terrestrial laser scanner set to $0.044^{\circ}$ resolution $(7.76 \mathrm{~mm}$ point distance at $10 \mathrm{~m}$ distance to scanner). A full $360^{\circ}$ horizontal and $150^{\circ}$ vertical angular range was covered, resulting in a maximum of 29 million points per scan. The scanner was placed on a tripod at $1.3 \mathrm{~m}$ above ground. Instrument heights, date and time, 
Fig. 2 Map of the ConFoBi research area with research plots marked as green circles. The dotted line indicates the border of the state of Baden-Württemberg to France and Switzerland

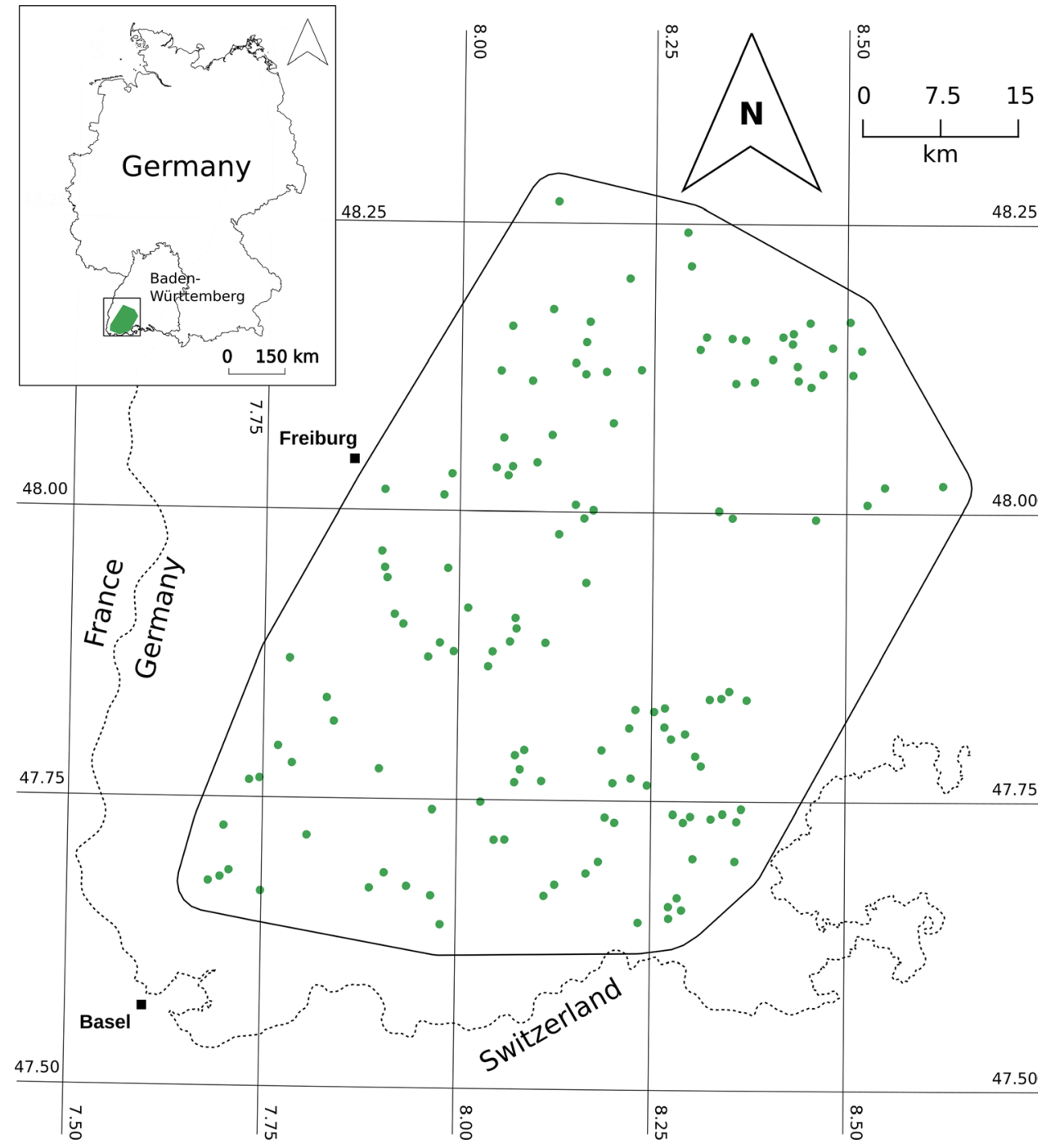

density. For all single scan values, we calculated the mean values per plot to compare it with the management intensity on the same spatial scale.

FRAC $=\frac{2 * \ln (0.25 * P)}{\ln (A)}$

$\mathrm{SSCI}=\operatorname{mean}(\mathrm{FRAC})^{\ln (\mathrm{ENL})}$

$\mathrm{ENL}=1 / \sum_{i=1}^{\text {itop }} p_{i}^{2}$

\section{Statistics}

We build generalized additive models (GAMs) (Wood 2019) to test the relationship of the SSCI value with the ForMI, 

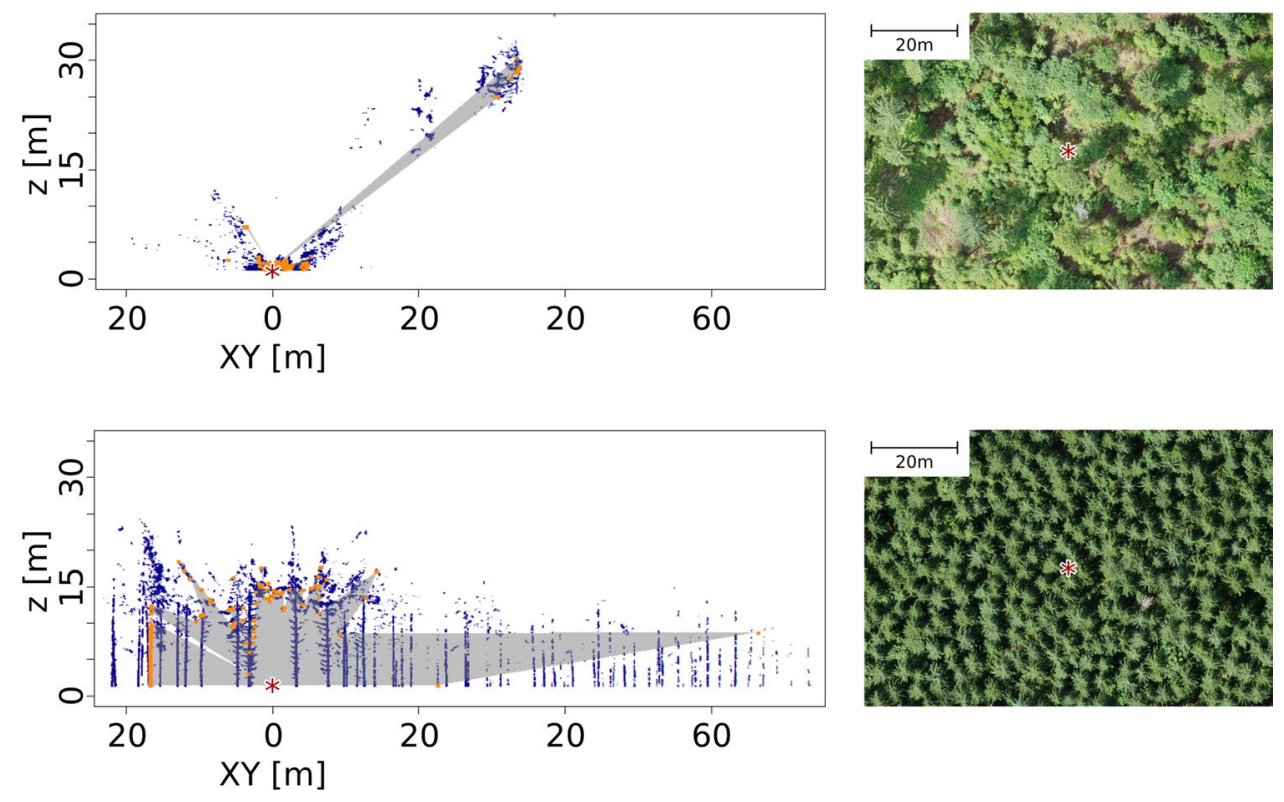

Fig. 3 Left panel: examples of different vertical scanlines from a TLS data for Stand Structural Complexity Index calculation. The red starsymbol is the position of the device; blue points illustrate the scanned points in a $20^{\circ}$ transect, orange points indicate the returns in the current scan column; the gray area shows the respective constructed polygon for the FRAC computation. The upper figure is an example for high structural complexity with a small area and a complex perim-

to answer research question one. We additionally tested the three parts of the ForMI (Inonat, Iharv, Idwcut) as predictors of the SSCI using GAMs. In order to answer research question two, we tested the ENL as a measure of vertical layering and the TLS mean distance as a measure of vegetation density as response variables with the ForMI and the parts of the ForMI as predictors. Additionally, we tested the FRAC as second component of the SSCI. Moreover, to underline and compare the selection of the SSCI as suitable stand complexity indicator, we tested the relationship between selected common attributes of stand structure (Table 1) and forest management intensity. The statistics were carried out in the R statistical software version 3.5 (R Core Team 2016).

\section{Results}

\section{Inventory data of forest management intensity, remote sensing and stand structural attributes}

The ForMI can take values between zero (no management intensity) and three (high management intensity). The results of our study revealed a considerable spread of the forest management intensity ranging from an index value of 0.04 to 2.38 with a mean of 1.3 in the inventoried plots (Table 1). Similar to the ForMI, the stand structural complexity index eter of the gray polygon. The lower figure shows a polygon leading to low FRAC values with a large area and a less complex perimeter. The right panel shows ortho images of the respective forest plots with red stars indicating the scan positions. While the upper one shows different crown sizes of a partly regenerated stand, the lower one shows a homogeneous conifer forest

showed a wide range from 2.1 to 13.0 with a mean of 4.3 (Table 1), which covers the full range found in earlier studies (Ehbrecht et al. 2017; Stiers et al. 2018). Several non-remote sensing stand structural attributes are presented in Table 1 to indicate the gradients of the inventoried plots in mature mountain forests.

\section{Results of the statistical analyses}

The results of the GAMs did not prove a significant relationship between the SSCI and the ForMI (Table 2), but the components lharv and Inonat showed significant relationships to the SSCI (Fig. 5).

We found relationships between the TLS mean distance and the proportion of non-native tree species, the harvesting intensity and the ForMI itself. Despite being significant, the deviances explained by these models are quite low (3-38\%) and the relationships are weak (Adjusted $R^{2}: 0.03-0.36$ ) (Table 2, Fig. 5).

Next to the remote sensing parameters, we found weak relationships of forest management intensity and common stand structural attributes such as the basal area and Gini coefficient of DBH (Table 2, Figure SI1). Similar as to the remote sensing results, Inonat and Iharv showed some significant relationships with these attributes and the quadratic mean DBH in contrast to the Idwcut (Table 2, Figure SI1). 


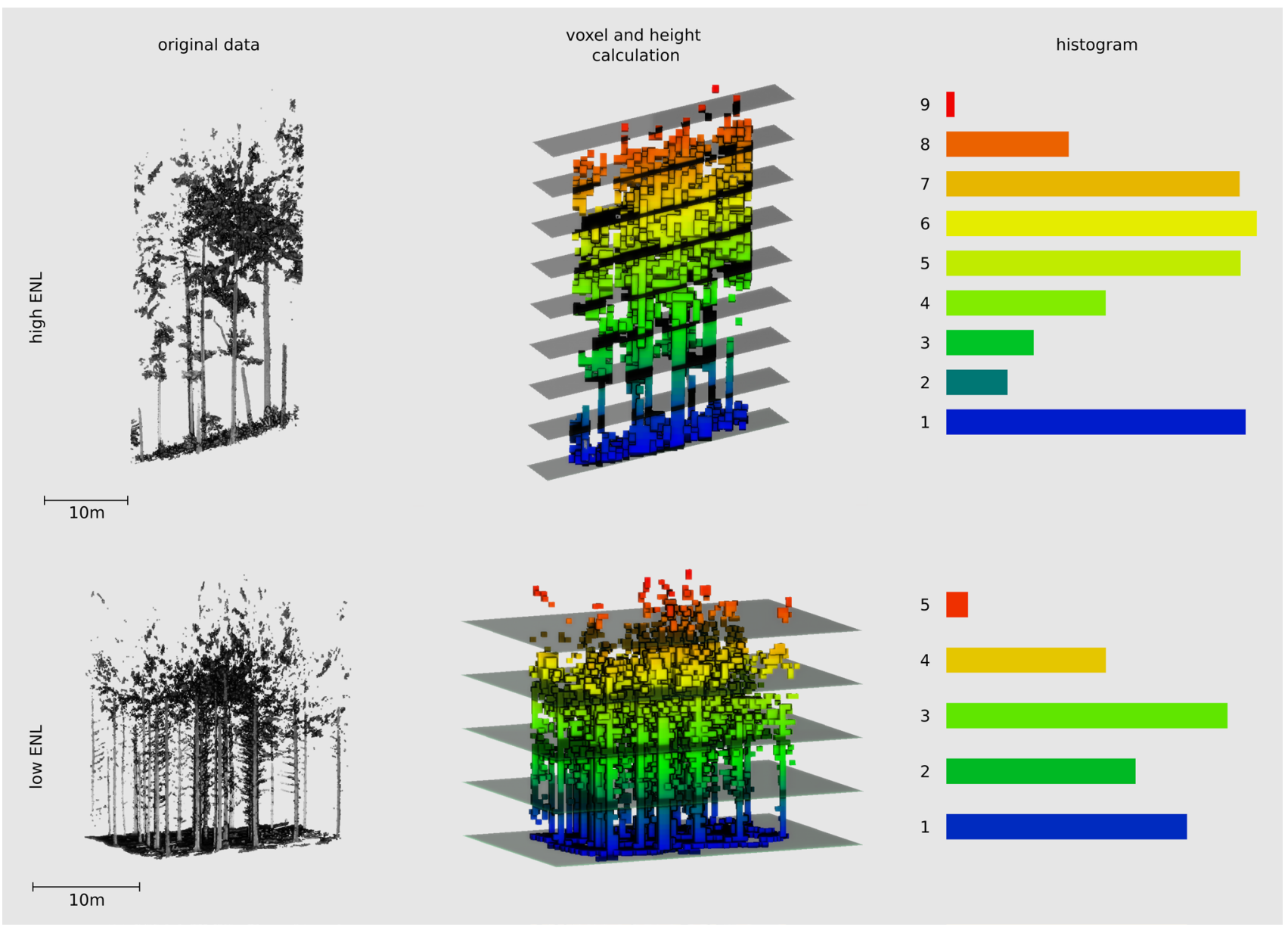

Fig. 4 Conceptual graph for the ENL computation. The raw points of a $20 \times 20 \mathrm{~m}$ plot (left panel) are simplified to $10 \mathrm{~cm}^{3}$ presence/ absence voxels. The height of these bins over the ground is calculated and the voxels are assigned to height bins according to their distance to the ground (central panel). From these height bins a normalized

\section{Discussion}

Our results did not reveal significant relationships between forest management intensity and stand structural complexity measured by terrestrial laser scanning. We cannot confirm the hypotheses that an intermediate management intensity leads to a greater stand structural complexity. Despite the ForMI being insignificant in relation to the SSCI, we found weak responses of stand structural complexity to harvesting intensity (Iharv) and the ratio of non-native tree species (Inonat). Therefore, we consider a discussion of our results worth for two major reasons.

First, sustainable forest management in general, and close-to-nature forest management in particular, aims to mimic natural disturbance patterns to a certain degree (Bergeron et al. 1999; Franklin and Van Pelt 2004; Drever et al. 2006; Bauhus et al. 2013; Messier et al. 2013, 2019). As our study suggests, and has been shown in earlier histogram is computed which is the basis for the inverse SimpsonIndex (right panel, Eq. 2). The ENL is higher for higher stands with a more homogeneous height distribution of plant material. The upper row depicts a stand with a high ENL value while the lower one shows a stand with a low ENL value

studies that used TLS measures of stand complexity (Stiers et al. 2018) or other indexes (Storch et al. 2018), detectable differences in stand structural complexity that follow the respective management are limited. One of the major results is that up to a harvesting intensity of 0.6 the forest structure does not respond in a drastic way (Fig. 5). The strong increase in structural complexity with increasing harvesting intensity is plausible, since the harvest of trees leads to regeneration patches and thus a multilayered forest. Iharv does not take temporal dynamics into account; therefore high values can include harvesting operations that occurred longer times ago, which would allow the establishment of natural regeneration under a canopy layer of remaining trees. The possibly arising assumption that a lack of relationship of management and stand structural complexity might allow a higher management intensity without drastic changes in the stand structure can however not be made based on our results. The first reason is that in our 
Table 1 Summary statistics of the variables used in the statistical analyses across 135 one-hectare forest plots

\begin{tabular}{|c|c|c|c|}
\hline & Min & Max & Mean (SD) \\
\hline \multicolumn{4}{|l|}{ Management variables } \\
\hline Forest management intensity (ForMI) & 0.0 & 2.4 & $1.3(0.5)$ \\
\hline 1. Idwcut-Ratio of: & 0.0 & 1.0 & $0.4(0.3)$ \\
\hline $\begin{array}{l}\text { a. Artificial downed deadwood }\left(\mathrm{m}^{3} /\right. \\
\text { ha) }\end{array}$ & 0.0 & 177.2 & $20(23.7)$ \\
\hline b. Natural deadwood volume $\left(\mathrm{m}^{3} / \mathrm{ha}\right)$ & 5.8 & 461.4 & $56(62.4)$ \\
\hline 2. Inonat-Ratio of & 0.0 & 0.9 & $0.4(0.3)$ \\
\hline a. Volume in non-native $\left(\mathrm{m}^{3} / \mathrm{ha}\right)$ & 0.0 & 636.4 & $202.6(146.9)$ \\
\hline b. Native tree species $\left(\mathrm{m}^{3} / \mathrm{ha}\right)$ & 112.8 & 903.1 & $412(24.1)$ \\
\hline 3. Iharv-Ratio of: & 0.0 & 0.8 & $0.4(0.2)$ \\
\hline a. Harvested tree volume $\left(\mathrm{m}^{3} / \mathrm{ha}\right)$ & 0.0 & 801.8 & \\
\hline b. Maximum stand volume $\left(\mathrm{m}^{3} / \mathrm{ha}\right)$ & 349.8 & 1222.8 & $773.7(185.0)$ \\
\hline \multicolumn{4}{|l|}{ Remote sensing variables } \\
\hline $\begin{array}{l}\text { Stand structural complexity index } \\
\text { (SSCI) }\end{array}$ & 2.1 & 13.0 & $4.3(1.8)$ \\
\hline 1. Effective number of layers (ENL) & 7.0 & 27.2 & $16.1(4.2)$ \\
\hline $\begin{array}{l}\text { 2. Mean fractal dimension index } \\
\text { (MFRAC) }\end{array}$ & 1.3 & 4.0 & $1.7(0.4)$ \\
\hline TLS mean distance & 3.5 & 11.4 & $7.1(1.9)$ \\
\hline \multicolumn{4}{|l|}{ Stand structural attributes } \\
\hline Basal area $\left(\mathrm{m}^{2} / \mathrm{ha}\right)$ & 9.38 & 34.09 & $73.11(98)$ \\
\hline Gini coefficient of DBH per ha & 0.1 & 0.5 & $0.3(0.1)$ \\
\hline Quadratic mean DBH (cm) & 15.9 & 54.0 & $33.6(7.7)$ \\
\hline Number of stems per ha & 148 & 1297 & $458.8(217.4)$ \\
\hline Number of tree species per ha & 3 & 12 & $6.4(1.9)$ \\
\hline
\end{tabular}

research plots a relatively uniform forest type consisting of mixtures of Norway spruce, European beech and silver fir in mature age classes was present. Despite the gradient of management intensity, in close-to-nature management the removal of individual or small groups of crop trees is most common (Brang et al. 2014) hence more "extreme" forms of forest management such as clear-cuts were absent (Asbeck et al. 2019). This leads to the second limitation of the design resulting in weak relations of forest management intensity and stand structural complexity in our research plots. The one-hectare scale might not be the most appropriate unit to identify influences of forest management intensity on stand structural complexity. Despite being a common measure of recommendations for silvicultural approaches, most stands comprise areas that are larger than one hectare (Bergeron et al. 1999). The scale-issue is mentioned in several recommendations for forest management (Messier et al. 2019). Here it might be that one hectare is not representative for the disturbances that should be mimicked by management and larger spatial scales at the landscape matrix need to be considered (Franklin and Lindenmayer 2009; Schall et al. 2020). Besides the spatial scale, temporal dynamics are neither part of the ForMI nor the TLS based indices (Kahl and Bauhus 2014; Ehbrecht et al. 2017). We would expect that the time since last harvest is an important predictor that we did not include in our models as the regeneration representing the lower horizontal layer is an important driver of the stand complexity (Peck et al. 2014). This information is not available for our plots; therefore, we leave this question open for further research.

The second reason, why our results are important to report is that the method used to describe the stand structure using the SSCI might not be as sensitive to small-scale stand-level changes as expected and considered earlier (Ehbrecht et al. 2017; Stiers et al. 2018, 2020). Our study was to our best knowledge the first to analyze the influence of a continuous
Table 2 Results of the generalized additive models (GAMs) for the respective response variables predicted by the forest management intensity index and its' three components

\begin{tabular}{|c|c|c|c|c|}
\hline & \multicolumn{4}{|c|}{ Adjusted $R^{2}$, deviance explained (\%) and $p$ value } \\
\hline & ForMI & Idwcut & Inonat & Iharv \\
\hline \multicolumn{5}{|l|}{ Remote sensing variables } \\
\hline SSCI & n.s & n.s & $0.06(7)^{*}$ & $0.30(32)^{* * *}$ \\
\hline 1. ENL & n.s & n.s & $0.05(6)^{*}$ & n.s \\
\hline 2. MFRAC & n.s & $0.05(6)^{*}$ & $0.07(8)^{* *}$ & $0.36(38) * * *$ \\
\hline TLS mean distance & $0.03(3)^{*}$ & n.s & $0.13(14) * * *$ & $0.10(11)^{* *}$ \\
\hline \multicolumn{5}{|l|}{ Stand structural attributes } \\
\hline Basal area $\left(\mathrm{m}^{2} / \mathrm{ha}\right)$ & $0.03(3)^{*}$ & $0.06(6)^{* *}$ & $0.06(6)^{* *}$ & $0.27(28)^{* * *}$ \\
\hline Gini coefficient of DBH per ha & $0.03(4)^{*}$ & n.s & $0.19(21)^{* * *}$ & n.s \\
\hline Quadratic mean DBH $(\mathrm{cm})$ & n.s & n.s & $0.06(7)^{*}$ & $0.14(16)^{* * *}$ \\
\hline Number of stems per ha & n.s & n.s & n.s & n.s \\
\hline Number of tree species per ha & n.s & n.s & $0.06(8) *$ & n.s \\
\hline
\end{tabular}

Iharv proportion of harvested tree volume compared to the maximum volume, Inonat proportion of species not belonging to the natural forest community, Idwcut proportion of dead wood showing signs of saw cuts compared to deadwood originating from natural disturbances

Levels of significance: $* p<0.05 ; * * p<0.01 ; * * * p<0.001$ 

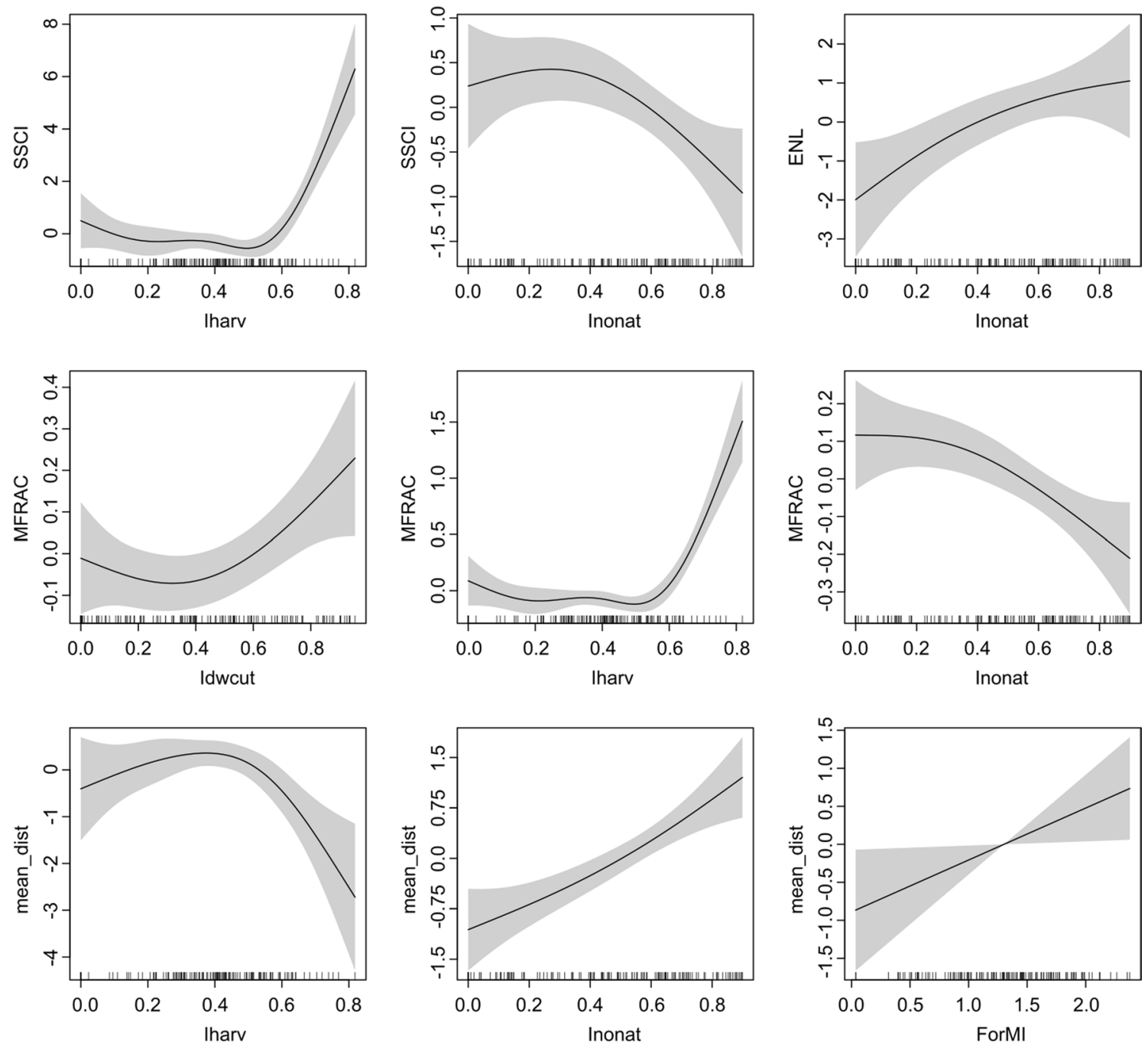

Fig. 5 Effect plots of the significant predictors of components of the stand structural complexity index based on the results of the generalized additive models (GAMs). The Stand Structural Complexity Index (SSCI) was significantly predicted by the ratio of harvested compared to the theoretical maximum volumes (Iharv) and the proportion of the non-natural tree species (Inonat). The Effective Number of Layers (ENL) was significantly predicted by the Inonat, the

indicator of forest management intensity on the stand structural complexity and we could not detect a strong and significant expected relationship. This might be related to the fact that we used three scans per one ha plots compared to nine scans in Ehbrecht et al. (2017). In an earlier study, a single TLS scan at the plot center was assumed to be representative of the surrounding stand (Ehbrecht et al. 2016) and to "provide an explanatory variable for the effects of forest management on biodiversity, productivity and ecosystem processes" (Ehbrecht et al. 2017). Another study quantifying the SSCI and indicating that tree species mixture can be detected by this index used nine scans per ha as well (Juchheim et al. 2019), which might partially explain the weak
MFRAC was predicted by all components of the ForMI, while the TLS mean distance (mean_dist) was predicted by Iharv, Inonat and the Forest Management Intensity (ForMI) itself. The greater the index values of the ForMI components, the greater the management intensity. The light-gray band indicates the $95 \%$ confidence interval. The rug plot at the bottom displays the observed values of the predictor

relationships that we found. The increase in the MFRAC with increasing values of Idwcut might indicate that the shape complexity might be raised due to relatively recent harvesting or thinning events, which are the main source of deadwood with saw marks. Yet, the very low $R^{2}$ value of 0.05 shows that this relationship is very weak. The responses of the MFRAC to Iharv and Inonat are very similar to the ones of the SSCI, which have been discussed earlier. However, the TLS mean distance and the ENL might indicate the expected relationships at least in response to the harvested proportion of the stand (Fig. 5). This is plausible since the structural complexity of stands in their maturity phase might be low due to the homogeneous closed canopy, similar to the 
lower complexity of stands where natural regeneration is not yet established (Peck et al. 2014). This is in line with results from European beech forests where only primary forests had a significantly higher structural complexity than managed forests, while stands in relatively recently established national parks were not distinguishable by the SSCI from managed ones (Stiers et al. 2018). The TLS mean distance is a simple measurement of how far the scanner can penetrate into a forest, but is limited to the maximum distance the scanner can cover (120 $\mathrm{m}$ in this case). Therefore, it is explicable that mostly planted, single layered stands with a high share of non-natural trees show a significantly higher value of the TLS mean distance compared to more complex stands originating from natural regeneration of multiple tree species (Müller et al. 2012). We can depict this information clearly from the fact that the Inonat is significantly related to the basal area and the Gini coefficient of the DBH. Plots with a high share of non-native species have a higher basal area linked with a decreasing Gini coefficient, indicating large and uniform trees. This effect might of course be different in other study systems. In contrast, with increasing harvesting intensity (Iharv) the TLS mean distance increases slightly due to the removal of trees and decreases when there is little plant material left that could reflect a laser pulse, or if dense regeneration occurs which potentially limits the line of sight. The ENL shows a similar pattern since it is mostly sensitive to a multilayered canopy (Ehbrecht et al. 2016) which is absent in dense, mono-species as well as in more intensively harvested stands. This is an indication that the harvesting intensity is one of the driving factors for the stand structure according to these metrices, even if our low model qualities clearly show the need for further investigations in this direction. Improved remote sensing methods of measuring stand structural complexity as well as considering a wider gradient of spatial and temporal scales beyond the one-hectare level might deliver different results than found in this study.

\section{Conclusions}

The improved understanding of the relation of forest management intensity and stand structural complexity allows forest managers to guide their management toward a desired stand structure. We deliver a first step for developing smarter management options for structurally more complex forests, that are potentially more resilient to climate change and the associated altering disturbances (Bauhus et al. 2009; Messier et al. 2013; Seidl et al. 2017). This study shows that the relationship between stand structure and forest management intensity is, while plausible, not trivial to demonstrate. We might conclude that forest managers have a relative wide range of choices, such as altering the harvesting intensity or increasing the amount of natural deadwood, to adapt forests comparable to the ones inventoried here to future challenges, since management intensity in CTNFM does not seem to change the forest structure drastically. The remote sensing based methods show at least comparable performance to conventional forest inventory metrics which are commonly more time consuming to perform.

Supplementary Information The online version of this article (https:// doi.org/10.1007/s10342-021-01361-4) contains supplementary material, which is available to authorized users.

Acknowledgements This study was funded by the German Research Foundation (DFG Project GRK 2123). We are grateful to our field assistants J. Großmann and Joel Wieser for data collection.

Funding Open Access funding enabled and organized by Projekt DEAL.

Open Access This article is licensed under a Creative Commons Attribution 4.0 International License, which permits use, sharing, adaptation, distribution and reproduction in any medium or format, as long as you give appropriate credit to the original author(s) and the source, provide a link to the Creative Commons licence, and indicate if changes were made. The images or other third party material in this article are included in the article's Creative Commons licence, unless indicated otherwise in a credit line to the material. If material is not included in the article's Creative Commons licence and your intended use is not permitted by statutory regulation or exceeds the permitted use, you will need to obtain permission directly from the copyright holder. To view a copy of this licence, visit http://creativecommons.org/licenses/by/4.0/.

\section{References}

Acker SA, Sabin TE, Ganio LM, McKee WA (1998) Development of old-growth structure and timber volume growth trends in maturing Douglas-fir stands. For Ecol Manag 104:265-280. https://doi. org/10.1016/S0378-1127(97)00249-1

Asbeck T, Pyttel P, Frey J, Bauhus J (2019) Predicting abundance and diversity of tree-related microhabitats in Central European montane forests from common forest attributes. For Ecol Manag 432:400-408. https://doi.org/10.1016/j.foreco.2018.09.043

Atkins JW, Bond-Lamberty B, Fahey RT et al (2020) Application of multidimensional structural characterization to detect and describe moderate forest disturbance. Ecosphere. https://doi.org/10.1002/ ecs 2.3156

Augustynczik ALD, Asbeck T, Basile M et al (2019) Diversification of forest management regimes secures tree microhabitats and bird abundance under climate change. Sci Total Environ 650:27172730. https://doi.org/10.1016/j.scitotenv.2018.09.366

Bauhus J, Puettmann K, Messier C (2009) Silviculture for oldgrowth attributes. For Ecol Manag 258:525-537. https://doi. org/10.1016/j.foreco.2009.01.053

Bauhus J, Puettmann KJ, Kuehne C (2013) Close-to-nature forest management in Europe: does it support complexity and adaptability of forest ecosystems? In: Messier C, Puettmann KJ, Coates KD (eds) Managing forests as complex adaptive systems: building resilience to the challenge of global change. Routledge, London, pp 187-213

Bergeron Y, Harvey B, Leduc A, Gauthier S (1999) Forest management guidelines based on natural disturbance dynamics: stand- and 
forest-level considerations. For Chron 75:49-54. https://doi. org/10.5558/tfc75049-1

Berryman S, McCune B (2006) Estimating epiphytic macrolichen biomass from topography, stand structure and lichen community data. J Veg Sci 17:157-170. https://doi.org/10.1658/11009233(2006)17[157:EEMBFT]2.0.CO;2

Brang P, Spathelf P, Larsen JB et al (2014) Suitability of close-tonature silviculture for adapting temperate European forests to climate change. Forestry 87:492-503. https://doi.org/10.1093/ forestry/cpu018

Ćosović M, Bugalho M, Thom D, Borges J (2020) Stand structural characteristics are the most practical biodiversity indicators for forest management planning in Europe. Forests 11:343. https:// doi.org/10.3390/f11030343

del Río M, Pretzsch H, Alberdi I et al (2016) Characterization of the structure, dynamics, and productivity of mixed-species stands: review and perspectives. Eur J For Res 135:23-49. https://doi. org/10.1007/s10342-015-0927-6

Drever CR, Peterson G, Messier C et al (2006) Can forest management based on natural disturbances maintain ecological resilience? Can J For Res 36:2285-2299. https://doi.org/10.1139/x06-132

Ehbrecht MA (2018) Quantifying three-dimensional stand structure and its relationship with forest management and microclimate in temperate forest ecosystems. Georg-August-Universität Göttingen, Göttingen

Ehbrecht M, Schall P, Juchheim J et al (2016) Effective number of layers: a new measure for quantifying three-dimensional stand structure based on sampling with terrestrial LiDAR. For Ecol Manag 380:212-223. https://doi.org/10.1016/j.foreco.2016.09.003

Ehbrecht M, Schall P, Ammer C, Seidel D (2017) Quantifying stand structural complexity and its relationship with forest management, tree species diversity and microclimate. Agric For Meteorol 242:19. https://doi.org/10.1016/j.agrformet.2017.04.012

Ehbrecht M, Schall P, Ammer C et al (2019) Effects of structural heterogeneity on the diurnal temperature range in temperate forest ecosystems. For Ecol Manag 432:860-867. https://doi.org/10.1016/j. foreco.2018.10.008

Fox JW (2013) The intermediate disturbance hypothesis should be abandoned. Trends Ecol Evol 28:86-92. https://doi.org/10.1016/j. tree.2012.08.014

Franklin JF, Lindenmayer DB (2009) Importance of matrix habitats in maintaining biological diversity. Proc Natl Acad Sci U S A 106:349350. https://doi.org/10.1073/pnas.0812016105

Franklin JF, Van Pelt R (2004) Spatial aspects of structural complexity in old-growth forests. J For 102:22-28

Frey J, Joa B, Schraml U, Koch B (2019) Same viewpoint different perspectives - a comparison of expert ratings with a TLS derived forest stand structural complexity index. Remote Sens 11:1137. https://doi. org/10.3390/rs11091137

Frey J, Asbeck T, Bauhus J (2020) Predicting tree-related microhabitats by multisensor close-range remote sensing structural parameters for the selection of retention elements. Remote Sens 20:867

Gadow KV, Zhang CY, Wehenkel C et al (2012) Forest structure and diversity. In: Pukkala T, von Gadow K (eds) Continuous cover forestry. Springer, Dordrecht, pp 29-83

Holzwarth S, Thonfeld F, Abdullahi S et al (2020) Earth observation based monitoring of forests in germany: a review. Remote Sens 12:3570. https://doi.org/10.3390/rs12213570

Juchheim J, Ehbrecht M, Schall P et al (2019) Effect of tree species mixing on stand structural complexity. For Int J For Res. https://doi. org/10.1093/forestry/cpz046

Kahl T, Bauhus J (2014) An index of forest management intensity based on assessment of harvested tree volume, tree species composition and dead wood origin. Nat Conserv 7:15-27. https://doi. org/10.3897/natureconservation.7.7281
McElhinny C, Gibbons P, Brack C (2006) An objective and quantitative methodology for constructing an index of stand structural complexity. For Ecol Manag 235:54-71. https://doi.org/10.1016/j.forec o.2006.07.024

Messier C, Puettmann KJ, Coates KD (2013) Managing forests as complex adaptive systems: building resilience to the challenge of global change. Routledge, Abingdon

Messier C, Bauhus J, Doyon F et al (2019) The functional complex network approach to foster forest resilience to global changes. For Ecosyst 6:21. https://doi.org/10.1186/s40663-019-0166-2

Müller J, Mehr M, Bässler C et al (2012) Aggregative response in bats: prey abundance versus habitat. Oecologia 169:673-684. https://doi. org/10.1007/s00442-011-2247-y

Neumann M, Starlinger F (2001) The significance of different indices for stand structure and diversity in forests. For Ecol Manag 145:91-106

Peck JE, Zenner EK, Brang P, Zingg A (2014) Tree size distribution and abundance explain structural complexity differentially within stands of even-aged and uneven-aged structure types. Eur J For Res 133:335-346. https://doi.org/10.1007/s10342-013-0765-3

R Core Team (2016) R: a language and environment for statistical computing. R Foundation for Statistical Computing, Vienna

Sabatini F, Burrascano S, Lombardi F et al (2015) An index of structural complexity for Apennine beech forests. iForest 8:314-323. https:// doi.org/10.3832/ifor1160-008

Schall P, Gossner MM, Heinrichs S et al (2018a) The impact of evenaged and uneven-aged forest management on regional biodiversity of multiple taxa in European beech forests. J Appl Ecol 55:267-278. https://doi.org/10.1111/1365-2664.12950

Schall P, Schulze E-D, Fischer M et al (2018b) Relations between forest management, stand structure and productivity across different types of Central European forests. Basic Appl Ecol 32:39-52. https://doi. org/10.1016/j.baae.2018.02.007

Schall P, Heinrichs S, Ammer C et al (2020) Can multi-taxa diversity in European beech forest landscapes be increased by combining different management systems? J Appl Ecol 1365-2664:13635. https ://doi.org/10.1111/1365-2664.13635

Seidel D, Ehbrecht M, Puettmann K (2016) Assessing different components of three-dimensional forest structure with single-scan terrestrial laser scanning: a case study. For Ecol Manag 381:196-208. https://doi.org/10.1016/j.foreco.2016.09.036

Seidl R, Thom D, Kautz M et al (2017) Forest disturbances under climate change. Nat Clim Change 7:395-402. https://doi.org/10.1038/nclim ate3303

Seidel D, Ehbrecht M, Annighöfer P, Ammer C (2019a) From tree to stand-level structural complexity - which properties make a forest stand complex? Agric For Meteorol 278:107699. https://doi. org/10.1016/j.agrformet.2019.107699

Seidel D, Ehbrecht M, Dorji Y et al (2019b) Identifying architectural characteristics that determine tree structural complexity. Trees 33:911-919. https://doi.org/10.1007/s00468-019-01827-4

Senf C, Mori AS, Müller J, Seidl R (2020) The response of canopy height diversity to natural disturbances in two temperate forest landscapes. Landsc Ecol 35:2101-2112. https://doi.org/10.1007/s10980-02001085-7

Stiers M, Willim K, Seidel D et al (2018) A quantitative comparison of the structural complexity of managed, lately unmanaged and primary European beech (Fagus sylvatica L.) forests. For Ecol Manag 430:357-365. https://doi.org/10.1016/j.foreco.2018.08.039

Stiers M, Annighöfer P, Seidel D et al (2020) Quantifying the target state of forest stands managed with the continuous cover approachrevisiting Möller's "Dauerwald" concept after 100 years. Trees For People. https://doi.org/10.1016/j.tfp.2020.100004

Storch F, Dormann CF, Bauhus J (2018) Quantifying forest structural diversity based on large-scale inventory data: a new approach to support biodiversity monitoring. For Ecosyst 5:34. https://doi. org/10.1186/s40663-018-0151-1 
Storch I, Penner J, Asbeck T et al (2020) Evaluating the effectiveness of retention forestry to enhance biodiversity in production forests of Central Europe using an interdisciplinary, multi-scale approach. Ecol Evol. https://doi.org/10.1002/ece3.6003

Szmyt J (2014) Spatial statistics in ecological analysis: from indices to functions. Silva Fennica. https://doi.org/10.14214/sf.1008

Townsend CR, Scarsbrook MR, Dolédec S (1997) The intermediate disturbance hypothesis, refugia, and biodiversity in streams. Limnol Oceanogr 42:938-949. https://doi.org/10.4319/lo.1997.42.5.0938

Van Wagner CE (1982) Practical aspects of the line intersect method. Petawawa National Forestry Institute, Chalk River
Whitman AA, Hagan JM (2007) An index to identify late-successional forest in temperate and boreal zones. For Ecol Manag 246:144-154. https://doi.org/10.1016/j.foreco.2007.03.004

Wood S (2019) Package mgcv. https://cran.r-project.org/web/packages/ mgcv/mgcv.pdf. Accessed 27 Aug 2019

Publisher's Note Springer Nature remains neutral with regard to jurisdictional claims in published maps and institutional affiliations. 